\title{
Ultrathin yet transferrable Pt- or PtRu-decorated graphene films as efficient electrocatalyst for methanol oxidation reaction
}

\author{
Zhuchen $\mathrm{Tao}^{1 \dagger}$, Wei Chen ${ }^{2 \dagger}$, Jing Yang ${ }^{2}$, Xiangyang Wang ${ }^{1}$, Ziqi Tan ${ }^{1}$, Jianglin Ye ${ }^{1}$, \\ Yanxia Chen $^{2^{*}}$ and Yanwu $\mathrm{Zhu}^{1}$
}

Direct methanol fuel cell (DMFC) has been regarded as one of promising electric generators in portable electronic equipment and electric vehicles because of the high energy conversion efficiency and low pollutant emissions $[1,2]$. Electro-oxidation of methanol has been studied extensively in terms of its application in DMFC and related theoretical analysis [3-5]. To date, the most promising anode catalyst for methanol oxidation is platinum (Pt). However, the development of commercial Pt-based fuel cells has been limited by the toxicity of carbon monoxide, the high cost of Pt and the aggregation of catalyst particles [6-9]. Using binary or alloy catalysts is an effective strategy for the removal of $\mathrm{CO}$ from the catalyst surface [10-13]. Extensive research reveals that ruthenium $(\mathrm{Ru})$-modified Pt nanoparticles (Pt NPs) are efficient binary electro-catalysts for methanol oxidation reaction (MOR) [14]. The addition of $\mathrm{Ru}$ to Pt-based catalysts significantly lowers the overpotential in MOR and enhances the CO-tolerance through the 'bifunctional mechanism' [11,12,14-18].

Considerable efforts have been devoted to reducing the amount of Pt by using various Pt-carbon hybrids, such as Pt-carbon nanotubes (Pt-CNTs) [19], Pt-porous carbons [20], and Pt-graphene [21]. Graphene is such a substrate that has a large specific surface area (for high catalyst loading), good stability (for tolerance to harsh conditions) as well as a high electrical conductivity (for efficient electron transfer) and therefore has been considered as a promising catalyst carrier in DMFCs [22,23]. With oxygen-containing functional groups, graphene oxide
(GO) is able to promote the growth of the metal NPs [24], and thus hybridizing graphene materials derived from GO with catalytic metals has been developed $[25,26]$. Particularly, Pt-decorated three-dimensional (3D) graphene hybrids exhibit improved electro-catalytic performances owing to the excellent dispersion of Pt NPs in the porous carbon architectures [27-32]. However, the large amount of defects and impurity in the graphene derived from GO substantially hinders the electrical and mechanical properties of the hybrid catalysts $[33,34]$. The defects may cause the graphene-based hybrids significantly unstable under harsh electrochemical conditions because of higher activity at the sites of defects [35]; the re-stacking and agglomeration in GO-based materials also impede the functionalization of graphene in the hybrids. The good stability and excellent conductivity of graphene from chemical vapor deposition (CVD) bring a high-quality and neat platform to evaluate the role of carbon in catalytic hybrids [36], but the surface of graphene produced by CVD (CVDG) is inactive due to its high degree of graphitization and thus it is challenging to directly deposit highly dispersed metal NPs [37]. Till now, CVDG has not been used to carry metal NPs for catalysis.

Herein, we demonstrate that controlled dispersion of $\mathrm{Pt}$ NPs with special particle size is realized on gentlymodified CVDG using a mild and environmentally friendly reductant, ethylene glycol (EG), in a hydrothermal process. The obtained ultrathin Pt NPs/CVDG (Pt-CVDG) hybrid films are different from the previously reported hybrids in which pre-synthesized metal NPs

\footnotetext{
${ }^{1}$ CAS Key Laboratory of Materials for Energy Conversion; Department of Materials Science and Engineering; i-ChEM, University of Science and Technology of China, Hefei 230026, China

${ }^{2}$ Hefei National Laboratory for Physical Sciences at Microscale, Department of Chemical Physics; University of Science and Technology of China, Hefei 230026, China

${ }^{\dagger}$ These authors contributed equally to this paper.

* Corresponding authors (emails: yachen@ustc.edu.cn (Chen Y); zhuyanwu@ustc.edu.cn (Zhu Y))
} 
were hybridized with graphene substrates by covalent bonding [38], electrostatics [39] or ligand-metal ionligand bridges [40], as these kinds of connections often lead to dramatic decrease in catalytic activity. The PtCVDG films can be transferred to other substrates due to high mechanical strength of CVDG, using common method performed on intrinsic CVDG [41]. Due to the monolayer feature of CVDG, the mass loading of Pt in PtCVDG hybrids is above $80 \mathrm{wt} . \%$, much higher than that of traditional Pt-carbon hybrid catalyst (20 wt.\%) [28$31,42-48]$. The evaluation of Pt-CVDG catalysts for MOR shows a low onset potential at $0.40 \mathrm{~V} v s . \mathrm{Ag} / \mathrm{AgCl}$, and a high mass specific current density of $293.1 \mathrm{~mA} \mathrm{mg}^{-1}{ }_{\mathrm{Pt}}$ in forward scan, with a forward/reverse scan peak current ratio of 1.33 for a Pt loading of $3.15 \mu \mathrm{g} \mathrm{cm}^{-2}$ measured in the voltage range of $0-1.0 \mathrm{~V}$. When $\mathrm{Ru}$ is electrochemically deposited onto the surface of Pt-CVDG film (with a Pt loading of $5.49 \mu \mathrm{g} \mathrm{cm}^{-2}$ ), the onset potential of the $\mathrm{PtRu}-\mathrm{CVDG}$ film electrode (for a nominal $\mathrm{Pt}$ and $\mathrm{Ru}$ coverage ratio of 68:32) is $0.20 \mathrm{~V}$-more negative than that for Pt-CVDG film, and its mass activity $\left(280.3 \mathrm{~mA} \mathrm{mg}^{-1} \mathrm{Pt}\right.$ at $0.5 \mathrm{~V}$ vs. $\mathrm{Ag} / \mathrm{AgCl}$ ) is about 2.5 times better than the latter measured in the voltage range of -0.20 to $0.50 \mathrm{~V}$.

As shown in Fig. 1, monolayer graphene was synthesized on copper foils by a low pressure CVD [49], and then transferred onto $\mathrm{SiO}_{2} / \mathrm{Si}$ substrates [41]. Oxygen plasma treatment was carried out to create oxygen-containing functional groups, resulting in negative charges on the surface of the graphene [50]. Raman spectrum (Fig. S1b) of CVDG transferred on $\mathrm{Si} / \mathrm{SiO}_{2}$ confirms the features of uniform monolayer graphene with intensity ratio $(\sim 2.0)$ of $2 \mathrm{D}\left(2,682 \mathrm{~cm}^{-1}\right)$ to $\mathrm{G}$ $\left(1,584 \mathrm{~cm}^{-1}\right)$ band and the full width at half maximum (FWHM) $\left(33.1 \mathrm{~cm}^{-1}\right)$ of the 2D band. The absence of D $\left(1,350 \mathrm{~cm}^{-1}\right)$ band indicates the high quality of the CVDG prepared [51]. After being exposed to a mildly $\mathrm{O}_{2}$ plasma, the Raman spectrum in Fig. S1b shows the appearance of $\mathrm{D}$ band which is relevant to defects in graphitic materials, especially when compared to the G band [51]. However, the decrease in the $I_{\mathrm{D}} / I_{\mathrm{G}}$ ratio after the hydrothermal process (Fig. S1d) indicates that the gentle $\mathrm{O}_{2}$ plasma has mostly introduced oxygen-containing groups noncovalently-bonded in close proximity to the carbon atoms arranged in benzene rings [52]. After treatment with oxygen plasma from 1 to $8 \mathrm{~s}$, the sheet resistance is increased by about 1 to 3 times, which is still 1 to 2 order of magnitude higher than those from reduced graphene oxide (RGO), as shown in Fig. S1f and previous reports [53]. A gradual attenuation as well as a slight broadening of $2 \mathrm{D}$ band is observed with increase the exposure time from 1 to $8 \mathrm{~s}$ with a plasma power of $10 \mathrm{~W}$. But the FWHM of $2 \mathrm{D}$ peak recovers to the original value after hydrothermal process (Fig. S1e), further proving that the plasma treatment does not induce significant structural

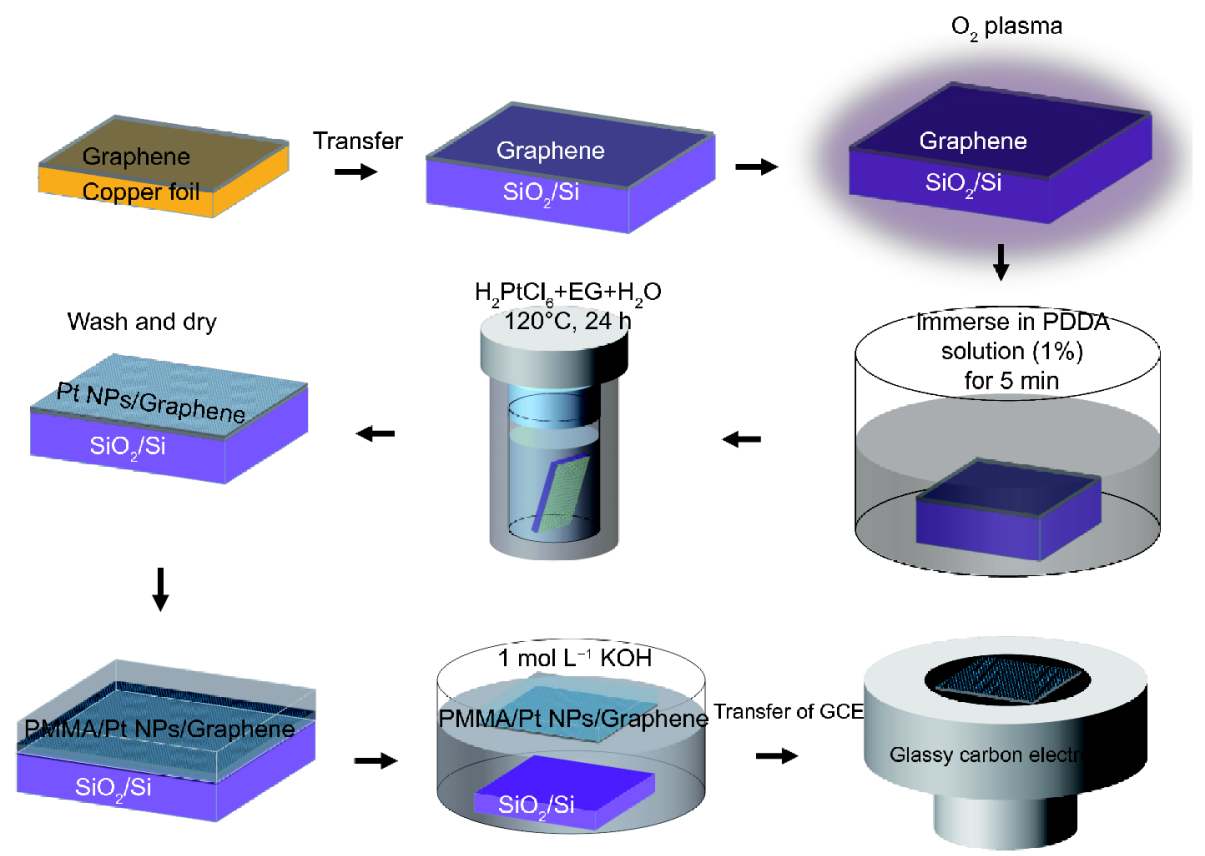

Figure 1 Schematic illustration of the synthesis of Pt-CVDG films. The procedure includes transfer of graphene films on desired substrates $\left(\mathrm{SiO}_{2} / \mathrm{Si}\right.$ 
defects in graphene. After the $\mathrm{O}_{2}$ plasma treatment, a cationic polyelectrolyte, poly(dimethyldiallylammonium chloride) (PDDA), was applied on the negatively charged CVDG, resulting in a positively-charged surface [54]. After the sequential washing and drying, the sample was sealed in a $50-\mathrm{mL}$ autoclave equipped with $30 \mathrm{~mL}$ of chloroplatinic acid $\left(\mathrm{H}_{2} \mathrm{PtCl}_{6}\right)$ solution in ethylene glycolwater $(5: 1)$ and kept at $180^{\circ} \mathrm{C}$ for $24 \mathrm{~h}$, for the deposition of Pt NPs [27,55]. Then the sample was taken out and washed several times with ethanol to remove residual chloride ions. The SEM images in Figs S2 and S3 show that the coverage of Pt NPs on CVDG is sensitive to the duration of $\mathrm{O}_{2}$ plasma treatment and that of PDDA treatment. The $\mathrm{O}_{2}$ plasma treatment for $4 \mathrm{~s}$ with a power of $10 \mathrm{~W}$ and a PDDA solution treatment for $5 \mathrm{~min}$ were typically used to obtain the samples with uniform coverage of $\mathrm{Pt}$ NPs on CVDG and minimizing the structural defects. Finally, the resulting sample was dried and transferred to a glassy carbon electrode (GCE) by a poly(methyl methacrylate) (PMMA) assisted method for electrochemical evaluation.

The as-prepared Pt-CVDG films were examined with scanning electron microscopy (SEM) and transmission electron microscopy (TEM). The mass density of Pt NPs can be adjusted by the concentration of $\mathrm{H}_{2} \mathrm{PtCl}_{6}$ in the hydrothermal process mentioned above; Pt-CVDG films with $\mathrm{Pt}$ loading of $6.24,5.49$ and $3.15 \mu \mathrm{g} \mathrm{cm}{ }^{-2}$ as determined by inductively coupled plasma mass spectrometer (ICP-MS), are denoted as Pt-CVDG-1, Pt-CVDG2, and Pt-CVDG-3, respectively. Based on the density of monolayer graphene $\left(0.77 \mathrm{mg} \mathrm{m}^{-2}\right)$, the Pt loading on PtCVDG films can be estimated as $89.0,87.6$ or 80.3 wt.\% for Pt-CVDG-1, Pt-CVDG-2 or Pt-CVDG-3, respectively. As shown in the SEM images in Fig. $2 a-c$, all samples have a uniform coverage of particles. The corresponding HRTEM images (Fig. 2g-i) clearly show the lattice fringes of Pt NPs, in which the typical interlayer distances of $0.223 \mathrm{~nm}$ and $0.195 \mathrm{~nm}$ are attributed to the interlayer spacings of (111) and (100) planes in face-centered cubic (fcc) Pt structure [56]. The Pt NPs aggregated on the graphene surface and had diameters of $2-5 \mathrm{~nm}$. The sizedistribution histograms (Fig. $2 \mathrm{j}-\mathrm{i}$ ) of the Pt NPs, obtained by measuring about 100 randomly-selected particles for each HRTEM image, show the average size of about 3.34, 3.29 and $3.25 \mathrm{~nm}$, for Pt-CVDG-1, Pt-CVDG-2 and PtCVDG-3, respectively. Although the monolayer graphene is invisible from the SEM and HRTEM images, the selected area electron diffraction (SAED) pattern (in Fig. $2 \mathrm{~m}$ ) taken on Pt-CVDG-2 shows the weak yet visible sixfold symmetry diffraction of monolayer graphene $[57,58]$, in addition to the multiple diffraction rings which are ascribed to Pt crystalline reflections of (111), (200), (220) and (311). Furthermore, X-ray photoelectron spectroscopy (XPS) was carried out to analyze the electronic structure of the Pt-CVDG and the typical XPS spectra of Pt-CVG-2 are shown in Fig. S4a, b. The C 1s spectrum of Pt-CVDG-2 in Fig. S4a has been fitted with four peaks. The most intense one at the binding energy of $284.7 \mathrm{eV}$ corresponds to $\mathrm{C}-\mathrm{C}$ bonding, and the other three peaks at 286.4, 287.9 and $288.9 \mathrm{eV}$ are ascribed to $\mathrm{C}-\mathrm{O}, \mathrm{C}=\mathrm{O}$ and $\mathrm{O}-\mathrm{C}=\mathrm{O}$, respectively, indicating the existence of oxygen containing functional groups in CVDG after $\mathrm{O}_{2}$ plasma treatment [27]. The $\mathrm{Pt} 4 \mathrm{f}$ spectrum shown in Fig. S4b consists of three pairs of doublets. The most intensive one at 71.5 and $74.75 \mathrm{eV}$ is contributed to $\mathrm{Pt}^{0} 4 \mathrm{f}_{7 / 2}$ and $\mathrm{Pt}^{0}$ $4 f_{5 / 2}$, while the other two weak doublets at 72.6/75.7 and $75.3 / 76.75 \mathrm{eV}$ correspond to $\mathrm{Pt}^{2+}$ and $\mathrm{Pt}^{4+}$, respectively. The metallic $\mathrm{Pt}^{0}$ contributes to $75.2 \%$ in the whole $\mathrm{Pt}$ content [59].

The electrochemical behavior of Pt-CVDG films was investigated by means of cyclic voltammograms (CVs) [27]. Fig. 3a shows the representative $\mathrm{CV}$ curves of PtCVDG/GCE and Pt/C/GCE in $1.0 \mathrm{~mol} \mathrm{~L}^{-1} \mathrm{H}_{2} \mathrm{SO}_{4}$. Electrochemically active surface area (ECSA) of all the above catalysts were estimated by calculating the coulombic charge for hydrogen adsorption and assuming that the oxidation of full monolayer of $\mathrm{H}$ atoms on polycrystalline $\mathrm{Pt}$ corresponds to a charge density of $210 \mu \mathrm{C} \mathrm{cm}^{-2}$ (Table 1 ). We can see that the very little electric double layer capacitance provided by CVDG compared to Pt-CVDG from Fig. S5 [36]. The results in Table 1 show that all the Pt-CVDG films have higher ECSA values than Pt/C and the highest ECSA is obtained from Pt-CVDG-3 (94.1 $\left.\mathrm{m}^{2} \mathrm{~g}^{-1}\right)$ which is about 3 times higher than that from $\mathrm{Pt} / \mathrm{C}$ catalyst $\left(28.5 \mathrm{~m}^{2} \mathrm{~g}^{-1}\right.$, $14.15 \mu \mathrm{g} \mathrm{cm}^{-2}$ ) under the same conditions, suggesting that the Pt-CVDG possesses a higher dispersion and utilization of Pt NPs. The peak near $0.0 \mathrm{~V}$ in Fig. 3a indicates the adsorption of hydrogen on the Pt fcc (100) surface site (I), and that near $-0.10 \mathrm{~V}$ is ascribed to the adsorption of hydrogen on the fcc (111) stage site (II) (Fig. 3a) [60]. It has been suggested that fcc (100) surface has better electro-catalytic activity than fcc (111) surface for MOR due to its higher oxygen species adsorption capacity [61]. The ratio of the peak current (I) to (II) adsorption of hydrogen are $0.80,0.81$ and 0.79 for PtCVDG-1, Pt-CVDG-2 and Pt-CVDG-3, which is much higher than 0.58 in $\mathrm{Pt} / \mathrm{C}$, indicating that the Pt-CVDG films are more MOR-active than $\mathrm{Pt} / \mathrm{C}$. The MOR performance was investigated by CVs in the mixture of 

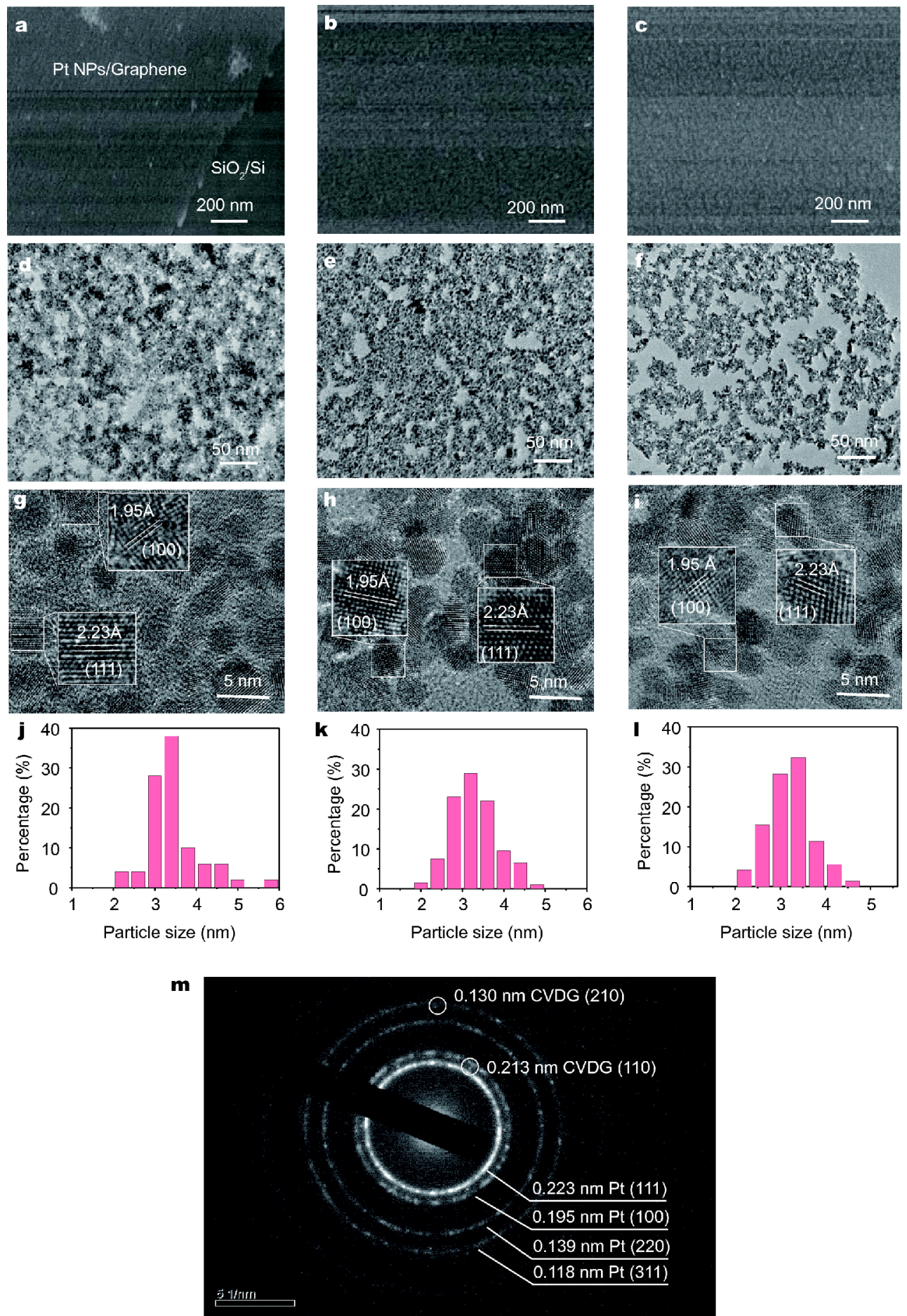

Figure 2 SEM images of Pt-CVDG films for (a) Pt-CVDG-1 (b) Pt-CVDG-2, and (c) Pt-CVDG-3. TEM images of Pt-CVDG films suspended on lacey support film corresponding to (d) Pt-CVDG-1, (e) Pt-CVDG-2 and (f) Pt-CVDG-3, respectively. HRTEM images of (g) Pt-CVDG-1, (h) PtCVDG-2, (i) Pt-CVDG-3, with insets showing the corresponding lattice fringes of the NPs marked in the dashed squares, respectively. Size distribution of Pt NPs from (j) Pt-CVDG-1, (k) Pt-CVDG-2 and (l) Pt-CVDG-3. (m) Typical SAED pattern taken from Pt-CVDG-2. 
Table 1 Catalytic performance of Pt-CVDG films with different loadings of Pt. ECSA and $I_{\mathrm{F}}, I_{\mathrm{R}}, I_{\mathrm{F}} / I_{\mathrm{R}}$ of Pt-CVDG films were investigated by means of CVs in $1.0 \mathrm{~mol} \mathrm{~L}^{-1} \mathrm{H}_{2} \mathrm{SO}_{4}$ solution and $1.0 \mathrm{~mol} \mathrm{~L}^{-1} \mathrm{H}_{2} \mathrm{SO}_{4}+2.0 \mathrm{~mol} \mathrm{~L}^{-1} \mathrm{CH}_{3} \mathrm{OH}$ solution, respectively.

\begin{tabular}{cccccc}
\hline Electrode & Loading amount of Pt $\left(\mathrm{mg} \mathrm{cm}^{-2}\right)$ & ECSA $\left(\mathrm{m}^{2} \mathrm{~g}^{-1}\right)$ & $I_{\mathrm{F}}\left(\mathrm{mA} \mathrm{mg}_{\mathrm{pt}}^{-1}\right)$ & $I_{\mathrm{R}}\left(\mathrm{mA} \mathrm{mg}_{\mathrm{Pt}}^{-1}\right)$ & $I_{\mathrm{F}} / I_{\mathrm{R}}$ \\
\hline Pt-CVDG-1 & 6.24 & 68.1 & 225.5 & 193.5 & 1.17 \\
Pt-CVDG-2 & 5.49 & 60.3 & 237.4 & 179.4 & 1.32 \\
Pt-CVDG-3 & 3.15 & 94.1 & 293.1 & 235.3 & 1.24 \\
Pt/C & 14.15 & 28.5 & 134 & 193.8 & 0.72 \\
\hline
\end{tabular}
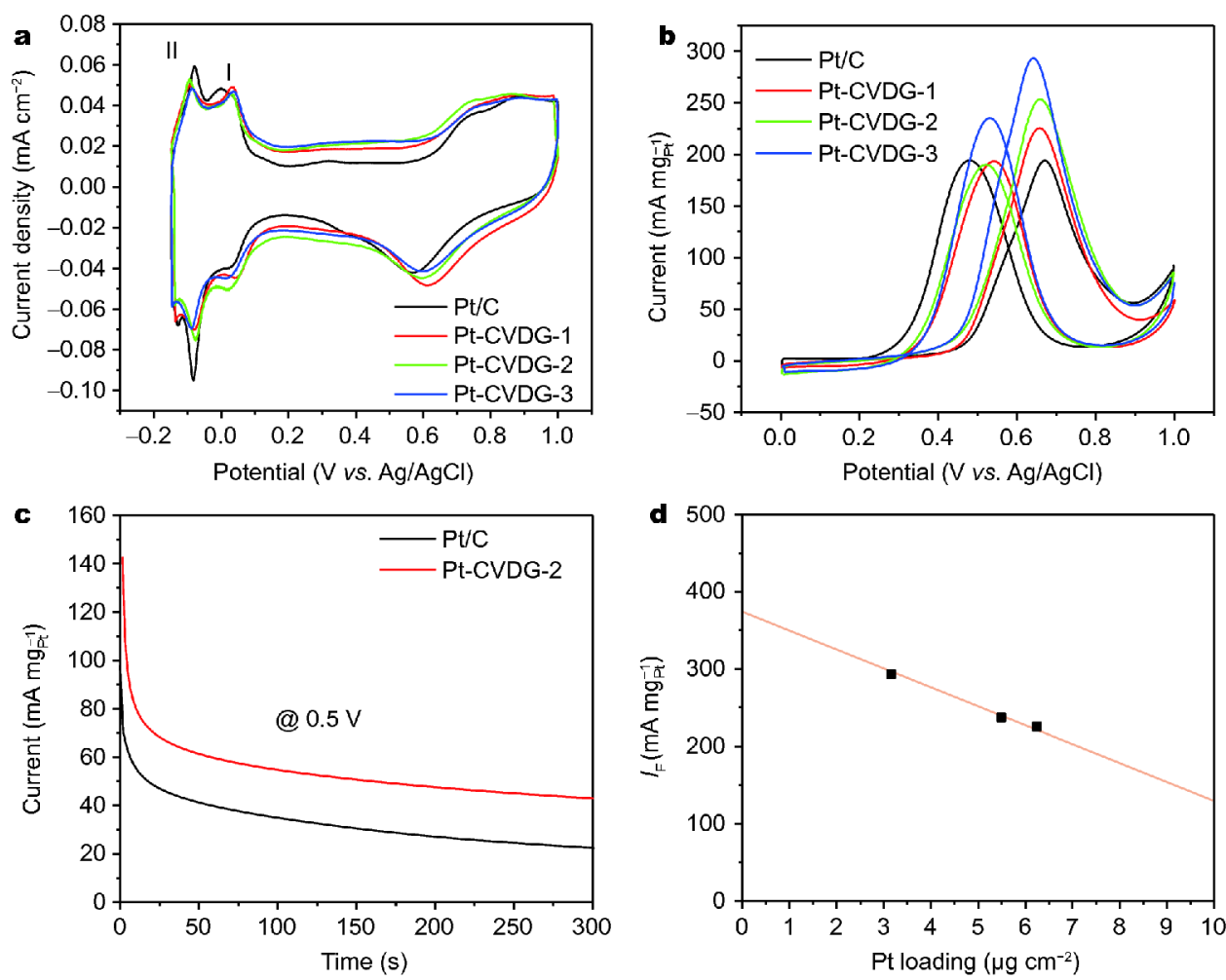

Figure $3 \mathrm{CVs}$ of Pt-CVDG films recorded in (a) $1.0 \mathrm{~mol} \mathrm{~L}^{-1} \mathrm{H}_{2} \mathrm{SO}_{4}$ solution at a scan rate of $20 \mathrm{mV} \mathrm{s}$, and (b) in $1.0 \mathrm{~mol} \mathrm{~L}^{-1} \mathrm{H}_{2} \mathrm{SO}_{4}+2.0 \mathrm{~mol} \mathrm{~L}^{-1}$ $\mathrm{CH}_{3} \mathrm{OH}$ solution at a scan rate of $20 \mathrm{mV} \mathrm{s}^{-1}$. (c) Current evolution for MOR on Pt/C and Pt-CVDG-2/GC electrodes at $0.50 \mathrm{~V}$. (d) Dependence of anodic peak current density in the forward scan on the Pt mass loading. The red line indicates a linear fitting of the data.

$1.0 \mathrm{~mol} \mathrm{~L}^{-1} \mathrm{H}_{2} \mathrm{SO}_{4}+2.0 \mathrm{~mol} \mathrm{~L}^{-1} \mathrm{CH}_{3} \mathrm{OH}$ solution (Fig. $3 \mathrm{~b})$. The specific current at the peak potential in the forward scan follows the order of Pt-CVDG-3 $\left(293.1 \mathrm{~mA} \mathrm{mg}_{\mathrm{Pt}}^{-1}\right)>$ Pt-CVDG-2 $\left(253.4 \mathrm{~mA} \mathrm{mg}^{-1} \mathrm{Pt}^{-}\right)>$ Pt-CVDG-1 (225.5 $\left.\mathrm{mA} \mathrm{mg}^{-1} \mathrm{pt}\right)$. The specific current at the peak potential decreases with the increase of $\mathrm{Pt}$ loading, due to the agglomeration of NPs. And a slight increase of the onset potential for MOR (forward scan) is observed when comparing Pt-CVDG with Pt/C. It is worth noting that Pt-CVDG has a Pt mass loading of more than 80 wt.\%, while the $\mathrm{Pt}$ loading in $\mathrm{Pt} / \mathrm{C}$ is 20 wt.\%. To investigate the long-term stability, chron- oamperometric measurements of Pt-CVDG-2 and Pt/C were performed at $0.50 \mathrm{~V}$ for $300 \mathrm{~s}$. As shown in Fig. 3c, Pt-CVDG-2 retains the higher oxidation current over the testing time, displaying the better electro-catalytic durability than $\mathrm{Pt} / \mathrm{C}$ catalysts for MOR. On the other hand, we also calculated the ratio of forward-scan peak current $\left(I_{\mathrm{F}}\right)$ versus reverse-scan peak current $\left(I_{\mathrm{R}}\right), I_{\mathrm{F}} / I_{\mathrm{R}}$, which is a key index for evaluating the catalyst tolerance to the accumulation of intermediate carbonaceous species. The ratio for Pt-CVDG-1, Pt-CVDG-2, PtCVDG-3 and commercial Pt/C is calculated as 1.17, 1.33, 1.24 and 0.72, respectively. Thus Pt-CVDG films 

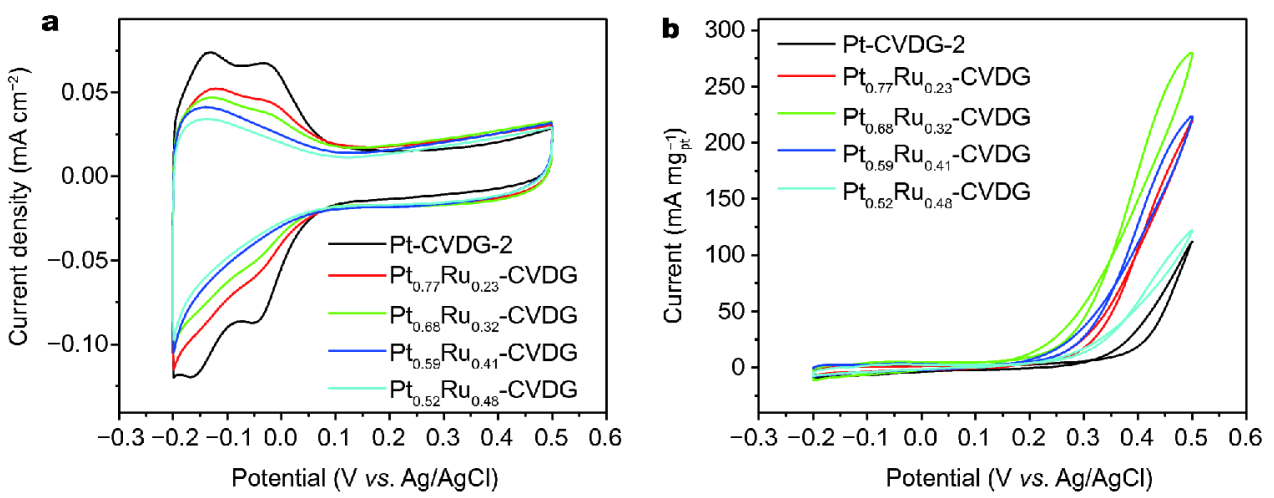

Figure 4 CVs of Pt-CVDG-2 and PtRu-CVDG with different Pt/Ru ratios recorded in (a) $0.1 \mathrm{~mol} \mathrm{~L}^{-1} \mathrm{HClO}_{4}$ solution at a scan rate of $50 \mathrm{mV} \mathrm{s}$, and (b) $0.1 \mathrm{~mol} \mathrm{~L}^{-1} \mathrm{HClO}_{4}+2.0 \mathrm{~mol} \mathrm{~L}^{-1} \mathrm{CH}_{3} \mathrm{OH}$ solution at a scan rate of $20 \mathrm{mV} \mathrm{s}^{-1}$.

generally have less carbonaceous accumulation and hence are much more tolerant toward $\mathrm{CO}[27,62]$. Both the mass activity and the anti-poisoning ability of Pt-CVDG films are superior to most of Pt-based nanostructures with Pt NPs about $3 \mathrm{~nm}$ in diameter (Table S1, Supporting information) [28-31,42,43,45-47]. All the results above indicate that with ultrahigh ECSA and a record-high mass activity for MOR, Pt-CVDG films possess much higher catalytic efficiency and utilization than commercial $\mathrm{Pt} / \mathrm{C}$.

Such high utilization of Pt atoms may be due to the uniform distribution and sub-monolayer coverage of $\mathrm{Pt}$ NPs on the CVDG, and the preferential fcc (100) orientation of Pt NPs is another reason for their high MOR activity. Based on the above data, we prepared samples of three different Pt loadings. The mass specific $I_{\mathrm{F}}$ increases with the decrease of loading, due to the agglomeration of Pt NPs. From the linear fitting of mass specific $I_{\mathrm{F}}$ versus Pt mass loading (Fig. 3d), the highest mass peak current of Pt NPs in the hybrid films is estimated to be $362 \mathrm{~mA} \mathrm{mg}^{-1}$ Pt. Thus Pt-CVDG-3 achieves $70 \%$ of the maximum catalytic capacity of $\mathrm{Pt}$ NPs toward MOR, while those of most results reported in literatures are lower than about $200 \mathrm{~mA} \mathrm{mg}^{-1} \mathrm{Pt}$ under similar conditions $[28-32,42]$.

To further improve the MOR activity at lower potentials for practical DMFC applications, $\mathrm{Ru}$ was electrochemically deposited onto the Pt-CVDG films. With balanced coverage and dispersion, Pt-CVDG-2 was used for preparing PtRu-CVDG electrode. Fig. 4a shows the CV curves in $0.1 \mathrm{~mol} \mathrm{~L}^{-1} \mathrm{HClO}_{4}$ solution for PtCVDG-2 and $\mathrm{Pt}_{x} \mathrm{Ru}_{y}$-CVDG electrodes ( $x$ and $y$ represent the nominal coverage of $\mathrm{Pt}$ and $\mathrm{Ru}$ at the surface with $x$ $+y=1$ ), which were prepared by depositing $\mathrm{Ru}$ for 20,40 , 60 and 80 potential cycles, respectively, in the potential range of $-0.10-0.20 \mathrm{~V}$ and at a scan rate of $50 \mathrm{mV} \mathrm{s}^{-1}$. To further evaluate the chemical composition of the PtRuCVDG hybrids, XPS were carried out on PtRu-CVDG, as shown in Fig. S4c. The peak at about $462 \mathrm{eV}(\mathrm{Ru} 3 \mathrm{p})$ illustrates the existence of $\mathrm{Ru}$. The chemical state of $\mathrm{Ru}$ has been further confirmed by using the Ru $3 p$ spectrum rather than $\mathrm{Ru} 3 \mathrm{~d}$ because of the overlap between the $\mathrm{Ru}$ $3 \mathrm{~d}$ and $\mathrm{C} 1 \mathrm{~s}$ spectra. As shown in Fig. S4d, the Ru $3 \mathrm{p}_{3 / 2}$ spectrum could be fitted into three peaks located at 462.2 , 464.3 and $466.3 \mathrm{eV}$, corresponding to metallic $\mathrm{Ru}, \mathrm{RuO}_{2}$ and $\mathrm{RuO}_{x} \mathrm{H}_{y}$, respectively. The formation of oxide states might result from the slight oxidation of $\mathrm{Ru}$ upon exposure to air. The MOR activity of $\mathrm{Pt}_{x} \mathrm{Ru}_{y}$-CVDG films was measured by $\mathrm{CV}$ in a mixture solution containing $0.1 \mathrm{~mol} \mathrm{~L}^{-1} \mathrm{HClO}_{4}+2.0 \mathrm{~mol} \mathrm{~L}^{-1} \mathrm{CH}_{3} \mathrm{OH}$. From Fig. $4 \mathrm{~b}$, the mass specific current density of PtRu-CVDG film catalysts at $0.50 \mathrm{~V}$ are 222.5, 280.3, 223.75 and $122.4 \mathrm{~mA} \mathrm{mg}^{-1} \mathrm{Pt}$ after deposition of $\mathrm{Ru}$ for $20,40,60$ and 80 potential cycles, respectively, all higher than $111.9 \mathrm{~mA} \mathrm{mg}_{\mathrm{Pt}}^{-1}$, of the pristine Pt-CVDG-2 at $0.50 \mathrm{~V}$. The highest MOR current is obtained from PtRu-CVDG film with the nominal Ru coverage $32 \%$, which was about 2.5 times higher than pristine Pt-CVDG-2 at $0.50 \mathrm{~V}$. The onset potential of $\mathrm{Pt}_{0.68} \mathrm{Ru}_{0.32}$-CVDG for MOR shifts to $0.25 \mathrm{~V}$, which is about $0.20 \mathrm{~V}$ more negative than that from Pt-CVDG-2 $(0.45 \mathrm{~V})$. The higher MOR activity of PtRu-CVDG films may be related to the highly dispersed capping-agent-free Pt NPs on CVDG and the good distribution of Ru on Pt NPs [63], and it is well accepted that the strong adsorption of hardly-oxidized $\mathrm{CO}$ on $\mathrm{Pt}$ surface leads to the self-poisoning [8]. The higher MOR activity for PtRu can be explained by two effects: 1) ensemble effect in which $\mathrm{Ru}$ adsorbs $\mathrm{OH}$ at the lower potential than $\mathrm{Pt}$ so that $\mathrm{CO}$ adsorbed on $\mathrm{Pt}$ can be oxidized to $\mathrm{CO}_{2}$ more easily; 2) electric effect in which the 
electron-charge transfer from $\mathrm{Ru}$ to $\mathrm{Pt}$ makes the $\mathrm{Pt}-\mathrm{CO}$ bond weaker and more suitable to oxidize methanol [16]. In the electro-deposition of $\mathrm{Ru}$ on Pt NPs [17], the contact between $\mathrm{Pt}$ and $\mathrm{Ru}$ increases with the number of deposition cycles, leading to the increased catalytic activity till the $\mathrm{Ru}$ coverage of $32 \%$ (Fig. $4 \mathrm{~b}$ ). But the further deposition of Ru may cover more Pt active sites, thus deteriorates the MOR activity for higher Ru contents [12].

In summary, we have demonstrated the preparation of Pt NPs films supported by CVDG using a simple and cost-effective method. The obtained Pt-CVDG films have advantages of uniform dispersion of Pt NPs, transferability and structural stability. When being used as an anode of DMFCs, the hybrid films exhibit excellent electro-catalytic activity and high poison tolerance, which can be attributed to the high utilization of $\mathrm{Pt}$ atoms dispersed on CVDG and the excellent electric conductivity of the films. Meanwhile, the mass load of $\mathrm{Pt}$ (80-89 wt.\%) in Pt-CVDG hybrids was greatly increased compared with that of traditional Pt-carbon hybrid catalyst (20 wt.\%). In addition, the introduction of $\mathrm{Ru}$ has further improved the methanol oxidation activity. The optimized PtRu-CVDG film has a nominal Pt and Ru coverage ratio of 2:1, from which the onset potential is $0.24 \mathrm{~V} v s . \mathrm{Ag} / \mathrm{AgCl}$ and the mass activity of $\mathrm{Pt}$ is 2.5 times higher than that of Pt-CVDG film. In principle, the method can be applied to other metal NPs for fabrication of high-performance CVDG-based nanostructure. We believe that this synthesis strategy can be also extended to more applications such as sensors, electronic devices, information storage, biomedicine and more.

\section{Received 22 August 2018; accepted 9 October 2018;}

published online 14 November 2018

1 Reddington E, Sapienza A, Gurau B, et al. Combinatorial electrochemistry: a highly parallel, optical screening method for discovery of better electrocatalysts. Science, 1998, 280: 1735-1737

2 Paik Y, Kim SS, Han OH. Methanol behavior in direct methanol fuel cells. Angew Chem Int Ed, 2008, 47: 94-96

3 Tiwari JN, Tiwari RN, Singh G, et al. Recent progress in the development of anode and cathode catalysts for direct methanol fuel cells. Nano Energy, 2013, 2: 553-578

4 Bahrami H, Faghri A. Review and advances of direct methanol fuel cells: Part II: Modeling and numerical simulation. J Power Sources, 2013, 230: 303-320

5 Tian XL, Wang L, Deng P, et al. Research advances in unsupported Pt-based catalysts for electrochemical methanol oxidation. J Energy Chem, 2017, 26: 1067-1076

6 Li M, Zhao Z, Cheng T, et al. Ultrafine jagged platinum nanowires enable ultrahigh mass activity for the oxygen reduction reaction. Science, 2016, 354: 1414-1419
7 Cao D, Lu GQ, Wieckowski A, et al. Mechanisms of methanol decomposition on platinum: a combined experimental and $a b$ initio approach. J Phys Chem B, 2005, 109: 11622-11633

8 Chen YX, Miki A, Ye S, et al. Formate, an active intermediate for direct oxidation of methanol on Pt electrode. J Am Chem Soc, 2003, 125: 3680-3681

9 Xue Q, Xu G, Mao R, et al. Polyethyleneimine modified AuPd@PdAu alloy nanocrystals as advanced electrocatalysts towards the oxygen reduction reaction. J Energy Chem, 2017, 26: 1153-1159

10 Ma SY, Li HH, Hu BC, et al. Synthesis of low Pt-based quaternary PtPdRuTe nanotubes with optimized incorporation of Pd for enhanced electrocatalytic activity. J Am Chem Soc, 2017, 139: 5890-5895

11 Wei ZD, Li LL, Luo YH, et al. Electrooxidation of methanol on upd-Ru and upd-Sn modified Pt electrodes. J Phys Chem B, 2006, 110: 26055-26061

12 Yao Y, Cai J, Zheng Y, et al. Preparation of surfactant-free Pt and PtRu nanoparticles with high activity for methanol oxidation. Chin J Chem Phys, 2014, 27: 332-336

$13 \mathrm{Fu} \mathrm{QQ}, \mathrm{Li} \mathrm{HH}, \mathrm{Ma} \mathrm{SY}$, et al. A mixed-solvent route to unique $\mathrm{PtAuCu}$ ternary nanotubes templated from $\mathrm{Cu}$ nanowires as efficient dual electrocatalysts. Sci China Mater, 2016, 59: 112-121

14 Petrii OA. Pt-Ru electrocatalysts for fuel cells: a representative review. J Solid State Electrochem, 2008, 12: 609-642

15 Tao Q, Chen W, Yao Y, et al. Study on methanol oxidation at Pt and PtRu electrodes by combining in situ infrared spectroscopy and differential electrochemical mass spectrometry. Chin J Chem Phys, 2014, 27: 541-547

16 Chatterjee M, Chatterjee A, Ghosh S, et al. Electro-oxidation of ethanol and ethylene glycol on carbon-supported nano-Pt and -PtRu catalyst in acid solution. Electrochim Acta, 2009, 54: 72997304

17 Frelink T, Visscher W, van Veen JAR. Measurement of the Ru surface content of electrocodeposited PtRu electrodes with the electrochemical quartz crystal microbalance: implications for methanol and CO electrooxidation. Langmuir, 1996, 12: 37023708

18 Coutanceau C, Rakotondrainibé AF, Lima A, et al. Preparation of $\mathrm{Pt}-\mathrm{Ru}$ bimetallic anodes by galvanostatic pulse electrodeposition: characterization and application to the direct methanol fuel cell. J Appl Electrochem, 2004, 34: 61-66

19 Huang H, Sun D, Wang X. Low-defect MWNT-Pt nanocomposite as a high performance electrocatalyst for direct methanol fuel cells. J Phys Chem C, 2011, 115: 19405-19412

20 Jiang $\mathrm{H}$, Zhao $\mathrm{T}$, Li C, et al. Functional mesoporous carbon nanotubes and their integration in situ with metal nanocrystals for enhanced electrochemical performances. Chem Commun, 2011, 47: 8590-8592

21 Zhang H, Ren W, Guan C, et al. Pt decorated 3D vertical graphene nanosheet arrays for efficient methanol oxidation and hydrogen evolution reactions. J Mater Chem A, 2017, 5: 22004-22011

22 Huang W, Wang H, Zhou J, et al. Highly active and durable methanol oxidation electrocatalyst based on the synergy of platinum-nickel hydroxide-graphene. Nat Commun, 2015, 6: 10035

23 Dong L, Gari RRS, Li Z, et al. Graphene-supported platinum and platinum-ruthenium nanoparticles with high electrocatalytic activity for methanol and ethanol oxidation. Carbon, 2010, 48: 781-787 
24 Li Y, Gao W, Ci L, et al. Catalytic performance of Pt nanoparticles on reduced graphene oxide for methanol electro-oxidation. Carbon, 2010, 48: 1124-1130

25 Guo S, Dong S, Wang E. Three-dimensional Pt-on-Pd bimetallic nanodendrites supported on graphene nanosheet: facile synthesis and used as an advanced nanoelectrocatalyst for methanol oxidation. ACS Nano, 2010, 4: 547-555

26 Gotterbarm K, Späth F, Bauer U, et al. Reactivity of graphenesupported Pt nanocluster arrays. ACS Catal, 2015, 5: 2397-2403

27 Huang H, Yang S, Vajtai R, et al. Pt-decorated 3D architectures built from graphene and graphitic carbon nitride nanosheets as efficient methanol oxidation catalysts. Adv Mater, 2014, 26: 51605165

28 Bo X, Guo L. Simple synthesis of macroporous carbon-graphene composites and their use as a support for Pt electrocatalysts. Electrochim Acta, 2013, 90: 283-290

29 Choi SM, Seo MH, Kim HJ, et al. Synthesis of surfacefunctionalized graphene nanosheets with high Pt-loadings and their applications to methanol electrooxidation. Carbon, 2011, 49: 904-909

30 Huang H, Chen H, Sun D, et al. Graphene nanoplate-Pt composite as a high performance electrocatalyst for direct methanol fuel cells. J Power Sources, 2012, 204: 46-52

31 Li Y, Tang L, Li J. Preparation and electrochemical performance for methanol oxidation of Pt/graphene nanocomposites. Electrochem Commun, 2009, 11: 846-849

32 Zhang LS, Liang XQ, Song WG, et al. Identification of the nitrogen species on $\mathrm{N}$-doped graphene layers and $\mathrm{Pt} / \mathrm{NG}$ composite catalyst for direct methanol fuel cell. Phys Chem Chem Phys, 2010, 12: 12055

33 Bagri A, Mattevi C, Acik M, et al. Structural evolution during the reduction of chemically derived graphene oxide. Nat Chem, 2010, 2: $581-587$

34 Pei S, Cheng HM. The reduction of graphene oxide. Carbon, 2012, 50: $3210-3228$

35 Li N, Cao M, Hu C. Review on the latest design of graphene-based inorganic materials. Nanoscale, 2012, 4: 6205-6218

36 Yao Y, Chen W, Du Y, et al. An electrochemical in situ infrared spectroscopic study of graphene/electrolyte interface under attenuated total reflection configuration. J Phys Chem C, 2015, 119: 22452-22459

37 Chien CC, Jeng KT. Effective preparation of carbon nanotubesupported Pt-Ru electrocatalysts. Mater Chem Phys, 2006, 99: 8087

38 Zamborini FP, Hicks JF, Murray RW. Quantized double layer charging of nanoparticle films assembled using carboxylate $/\left(\mathrm{Cu}^{2+}\right.$ or $\left.\mathrm{Zn}^{2+}\right)$ /carboxylate bridges. J Am Chem Soc, 2000, 122: 45144515

39 Schmitt J, Decher G, Dressick WJ, et al. Metal nanoparticle/ polymer superlattice films: fabrication and control of layer structure. Adv Mater, 1997, 9: 61-65

40 Sarathy KV, Thomas PJ, Kulkarni GU, et al. Superlattices of metal and metal-semiconductor quantum dots obtained by layer-bylayer deposition of nanoparticle arrays. J Phys Chem B, 1999, 103: 399-401

41 Song J, Kam FY, Png RQ, et al. A general method for transferring graphene onto soft surfaces. Nat Nanotech, 2013, 8: 356-362

42 Zhou YG, Chen JJ, Wang F, et al. A facile approach to the synthesis of highly electroactive Pt nanoparticles on graphene as an anode catalyst for direct methanol fuel cells. Chem Commun, 2010, 46:
$5951-5953$

43 Liang Q, Zhang L, Cai M, et al. Preparation and charaterization of $\mathrm{Pt} /$ functionalized graphene and its electrocatalysis for methanol oxidation. Electrochim Acta, 2013, 111: 275-283

44 Mayavan S, Jang HS, Lee MJ, et al. Enhancing the catalytic activity of Pt nanoparticles using poly sodium styrene sulfonate stabilized graphene supports for methanol oxidation. J Mater Chem A, 2013, 1: 3489-3494

45 Qiu JD, Wang GC, Liang RP, et al. Controllable deposition of platinum nanoparticles on graphene as an electrocatalyst for direct methanol fuel cells. J Phys Chem C, 2011, 115: 15639-15645

46 Wang $\mathrm{L}$, Tian $\mathrm{C}$, Wang $\mathrm{H}$, et al. Mass production of graphene via an in situ self-generating template route and its promoted activity as electrocatalytic support for methanol electroxidization. J Phys Chem C, 2010, 114: 8727-8733

47 Rajesh, Paul RK, Mulchandani A. Platinum nanoflowers decorated three-dimensional graphene-carbon nanotubes hybrid with enhanced electrocatalytic activity. J Power Sources, 2013, 223: 23-29

48 Zhong JP, Fan YJ, Wang $\mathrm{H}$, et al. Copper phthalocyanine functionalization of graphene nanosheets as support for platinum nanoparticles and their enhanced performance toward methanol oxidation. J Power Sources, 2013, 242: 208-215

49 Li X, Cai W, An J, et al. Large-area synthesis of high-quality and uniform graphene films on copper foils. Science, 2009, 324: 13121314

50 Mao $\mathrm{H}$, Wang $\mathrm{R}$, Zhong J, et al. Mildly $\mathrm{O}_{2}$ plasma treated CVD graphene as a promising platform for molecular sensing. Carbon, 2014, 76: 212-219

51 Ferrari AC, Basko DM. Raman spectroscopy as a versatile tool for studying the properties of graphene. Nat Nanotech, 2013, 8: 235246

52 Nourbakhsh A, Cantoro M, Vosch T, et al. Bandgap opening in oxygen plasma-treated graphene. Nanotechnology, 2010, 21: 435203

53 Xiao N, Dong X, Song L, et al. Enhanced thermopower of graphene films with oxygen plasma treatment. ACS Nano, 2011, 5: 27492755

54 Bragaru A, Vasile E, Obreja C, et al. Pt nanoparticles on graphenepolyelectrolyte nanocomposite: Investigation of $\mathrm{H}_{2} \mathrm{O}_{2}$ and methanol electrocatalysis. Mater Chem Phys, 2014, 146: 538-544

55 Zhao J, Li H, Liu Z, et al. An advanced electrocatalyst with exceptional eletrocatalytic activity via ultrafine Pt-based trimetallic nanoparticles on pristine graphene. Carbon, 2015, 87: 116-127

56 Rhee CK, Kim BJ, Ham C, et al. Size effect of Pt nanoparticle on catalytic activity in oxidation of methanol and formic acid: comparison to $\mathrm{Pt}(111), \mathrm{Pt}(100)$, and polycrystalline Pt electrodes. Langmuir, 2009, 25: 7140-7147

57 Meyer JC, Geim AK, Katsnelson MI, et al. On the roughness of single- and bi-layer graphene membranes. Solid State Commun, 2007, 143: 101-109

58 Ghosh K, Kumar M, Wang H, et al. Facile decoration of platinum nanoparticles on carbon-nitride nanotubes via microwave-assisted chemical reduction and their optimization for field-emission application. J Phys Chem C, 2010, 114: 5107-5112

$59 \mathrm{Xu} \mathrm{X}$, Zhou Y, Lu J, et al. Single-step synthesis of PtRu/N-doped graphene for methanol electrocatalytic oxidation. Electrochim Acta, 2014, 120: 439-451

60 Clavilier J, Armand D. Electrochemical induction of changes in the distribution of the hydrogen adsorption states on $\mathrm{Pt}(100)$ and $\mathrm{Pt}$ (111) surfaces in contact with sulphuric acid solution. J Electroanal 
Chem Interfacial Electrochem, 1986, 199: 187-200

61 Herrero E, Franaszczuk K, Wieckowski A. Electrochemistry of methanol at low index crystal planes of platinum: an integrated voltammetric and chronoamperometric study. J Phys Chem, 1994, 98: 5074-5083

62 Sharma S, Ganguly A, Papakonstantinou P, et al. Rapid microwave synthesis of $\mathrm{CO}$ tolerant reduced graphene oxide-supported platinum electrocatalysts for oxidation of methanol. J Phys Chem C, 2010, 114: 19459-19466

63 Tripković AV, Popović KD, Grgur BN, et al. Methanol electrooxidation on supported Pt and PtRu catalysts in acid and alkaline solutions. Electrochim Acta, 2002, 47: 3707-3714

Acknowledgements We acknowledge the support from the National Natural Science Foundation of China (51322204 and 51772282), the
National Program on Key Basic Research Project (973 Program and 2015CB932300) and the Fundamental Research Funds for the Central Universities (WK2060140014 and WK2060140017).

Author contributions Tao $\mathrm{Z}$ designed and engineered the samples; Tao Z, Chen W and Yang J performed the experiments; Tao Z, Chen W, Yang J, Wang X, Tan Z and Ye J performed the data analysis; Tao Z wrote the paper with support from Zhu Y and Chen Y. All authors contributed to the general discussion.

Conflict of interest The authors declare no competing financial interest.

Supplementary information Experiment section and the supporting data are available in the online version of the paper. 

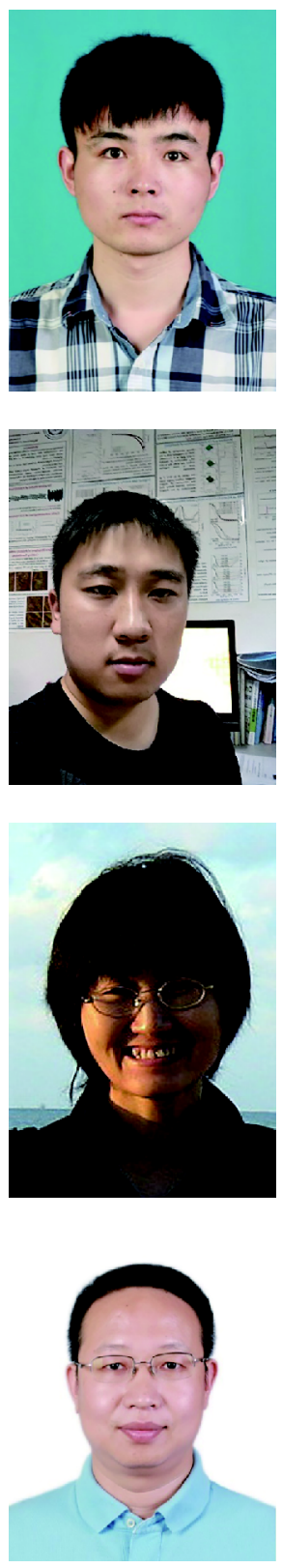

Zhuchen Tao received his bachelor's degree in materials chemistry from the University of Science and Technology of China (USTC) in 2012. Then, he pursues his PhD degree in materials physics and chemistry under the supervision of Prof. Yanwu Zhu at USTC. His research interest focuses on the electrocatalytic performance of carbon-related films.

Wei Chen is currently a PhD candidate at USTC in the group of Prof. Chen. His research focuses on using in-situ spectroscopic methods such as differential electrochemical mass spectrometry and in-situ electrochemical infrared spectrometry to study reaction mechanisms and kinetics of fundamental electrochemical reactions such as hydrogen evolution/oxidation, oxygen reduction, and formic acid oxidation reactions.

Yan-Xia Chen is a professor at USTC. She gained her PhD degree under the supervision of Prof. Zhong Qun Tian at Xiamen University, China. Her research covers spectro-electrochemistry, single crystal electrochemistry, and electrocatalysis and focuses on developing spectroscopic methods with both qualitative and quantitative analytical functions and using them in fundamental studies on electrochemical interfacial structure, reaction mechanisms, and kinetics of fuel cell processes.

Yanwu Zhu received his PhD in 2007 from the Department of Physics, National University of Singapore. After years as postdoctoral researcher at National University of Singapore and The University of Texas at Austin, he joined USTC as a professor in 2011. His current research interest includes the preparation of novel carbon materials and their applications in energy storage and conversion.

\section{超薄可转移的铂和铂钓修饰的石墨烯薄膜作为高效甲醇氧化催化剂}

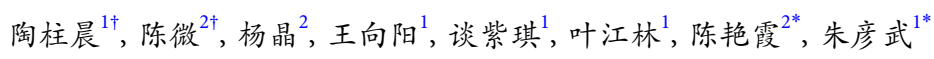

摘要 从氧化石墨中获得石墨烯材料在负载金属催化剂中具有很大的应用潜力, 但在通过化学气相沉积制备的高质量石墨烯(CVDG)上 均匀负载金属纳米粒子仍然是一个挑战. 我们成功制备了在CVDG上均匀负载具有约 $3.3 \mathrm{~nm}$ 尺寸的铂纳米粒子的超薄复合薄膜 $(\mathrm{Pt}-$ CVDG), 并且这种薄膜可通过类似CVDG转移的方法转移到目标衬底上. Pt-CVDG薄膜在甲醇催化氧化中表现出优异的性能, 具有高达 $94.1 \mathrm{~m}^{2} \mathrm{~g}^{-1} \mathrm{pt}$ 的电化学活性表面积, 并且在 $0.7 \mathrm{~V}$ 下具有 $293.1 \mathrm{~mA} \mathrm{mg} \mathrm{mt}^{-1}$ 的高质量活性电流密度, 该电流密度几乎是相同条件下商业 $\mathrm{Pt} / \mathrm{C}$ 的 两倍. 此外, 为进一步提高催化性能, 将钓沉积到Pt-CVDG薄膜上, 在Ru覆盖率达到 $50 \%$ 时得到比原始样品高 2 倍的催化电流密度且催化起 始电位降低 $0.2 \mathrm{~V}$. 同时这种基于CVDG的复合薄膜为评估Pt NPs-碳杂化催化剂性能的极限提供了一个简单模型. 